\title{
Clinical study of hypo/hyper thyroidism in dysfunctional uterine bleeding
}

\author{
Usharani N.*, Kaveri Shavi
}

Department of Obstetrics and Gynecology, Vijayanagara Institute of Medical Sciences, Ballari, Karnataka, India

Received: 07 July 2017

Accepted: 14 July 2017

\section{*Correspondence:}

Dr. Usharani N.,

E-mail: ushadrrani@gmail.com

Copyright: (C) the author(s), publisher and licensee Medip Academy. This is an open-access article distributed under the terms of the Creative Commons Attribution Non-Commercial License, which permits unrestricted non-commercial use, distribution, and reproduction in any medium, provided the original work is properly cited.

\begin{abstract}
Background: Dysfunctional uterine bleeding is one of the most frequently encountered condition in gynaecological practice. Thyroid hormones play a key role in the menstrual and reproductive function of women and thus thyroid dysfunction results in menstrual disturbances. The objective is to study the prevalence of thyroid disorders in patients with dysfunctional uterine bleeding.

Methods: This is a hospital based prospective observational study done in the department of Obstetrics and Gynaecology, Vijayanagara Institute of Medical Sciences, Ballari. The study period is from February 2016 to August 2016. In the study, 100 patients with dysfunctional uterine bleeding were included and evaluated for thyroid abnormality.

Results: Among 100 patients with DUB, thyroid disorders were prevalent in $24 \%$ of patients. Hypothyroidism was present in $22 \%$ and hyperthyroidism in $2 \%$ of the women with DUB. The commonest menstrual complaint associated with hypothyroidism was menorrhagia, seen in $54.54 \%$ of cases. In 2 patients with hyperthyroidism one each had menorrhagia and metropathia haemorrhagica.

Conclusions: Thyroid dysfunction is one of the important cause for DUB. Hypothyroidism is more commonly associated with DUB than hyperthyroidism. Evaluation of thyroid status is important in all patients with DUB to avoid unnecessary surgical interventions.
\end{abstract}

Keywords: Dysfunctional uterine bleeding, Hypothyroidism, Hyperthyroidism, Menorrhagia

\section{INTRODUCTION}

Abnormal uterine bleeding is a term used to describe any type of bleeding that does not fall within the normal range for amount, frequency, duration and cyclicity. ${ }^{1}$

Dysfunctional uterine bleeding (DUB) is defined as abnormal uterine bleeding in the absence of any palpable pelvic pathology and demonstrable extra genital causes. It occurs in $9-14 \%$ of women between menarche and menopause, significantly impacting quality of life and imposing financial burden. ${ }^{2}$ It is often difficult to identify the cause of abnormal bleeding even after a thorough history and physical examination. Thyroid hormones play a key role in the menstrual and reproductive function of women. Thyroid dysfunction is known to affect all aspects of reproductive function in the female.

The spectrum of thyroid disorders is associated with a variety of changes in reproductive function ranging from delayed onset of puberty, anovulatory cycles and abnormally high fetal wastage. The most common manifestation of hyperthyroidism is oligomenorrhoea and anovulation, whereas hypothyroidism, even in its subclinical form, may result in excessive menstrual bleeding and severe blood loss. ${ }^{3}$ Treating thyroid 
dysfunction early can reverse menstrual abnormalities and thus improve fertility.

The present study was undertaken to evaluate the thyroid function in patients having dysfunctional uterine bleeding and to assess the menstrual pattern in women with thyroid disorders.

\section{METHODS}

This is a hospital based prospective observational study conducted in the Department of Obstetrics and Gynaecology, Vijayanagara Institute of Medical Sciences (VIMS), Ballari, over a period between February 2016 to August 2016. One hundred women who presented with dysfunctional uterine bleeding to the out- patient department were recruited in this study.

\section{Inclusion criteria}

All cases provisionally diagnosed to have dysfunctional uterine bleeding from puberty to premenopausal age group were included in the study.

\section{Exclusion criteria}

Patients on drugs like antiepileptics, antipsychotics and hormonal therapy, IUCD users, women with thyroid carcinoma, bleeding disorders and with organic pelvic lesions were excluded from the study.

In all the patients, a detailed gynaecological history was obtained regarding age, bleeding pattern, onset, duration, quantity of bleeding and complaints regarding thyroid dysfunction. A complete examination including general examination, systemic examination and gynaecological examination was carried out. All routine blood investigations like haemoglobin, blood grouping, platelet count, bleeding time, clotting time were done. Specific investigations included pelvic ultrasound and Free T3, Free T4 and TSH levels (CLIA method).

Reference values

Free T3 (FT3) - 1.71-4.2 pg/ml

Free T4 (FT4) - 0.80-1.76 ng/dl

Thyroid stimulating hormone (TSH) - 0.35-5.5 $\mu \mathrm{IU} / \mathrm{ml}$.

\section{RESULTS}

Total number of DUB patients included in the study were 100 , out of which 24 cases $(24 \%)$ were having thyroid disorders. Age wise distribution of the DUB patients showed that most of them were in the age group of 31-40 years- $46(46 \%)$ followed by age group of 41-50 years $33(33 \%)$ (Table 1).
Table 1: Distribution of patients according to the age $(n=100)$.

\begin{tabular}{|lll|}
\hline Age group (in years) & No. of cases & $\%$ \\
\hline$<20$ & 02 & 02 \\
\hline $20-30$ & 15 & 15 \\
\hline $31-40$ & 46 & 46 \\
\hline $41-50$ & 33 & 33 \\
\hline$>50$ & 04 & 04 \\
\hline Total & 100 & 100 \\
\hline
\end{tabular}

Parity

Most of the cases had a parity of $3(36 \%)$, followed by para $2(24 \%)$. Four patients were nulliparous, and 5 were unmarried (Table 2).

Table 2: Distribution of patients according to the parity $(n=100)$.

\begin{tabular}{|lll|}
\hline & No. of patients & $\%$ \\
\hline Unmarried & 05 & 05 \\
\hline Nulliparous & 04 & 04 \\
\hline Primipara & 05 & 05 \\
\hline Para 2 & 24 & 24 \\
\hline Para 3 & 36 & 36 \\
\hline Para 4 & 19 & 19 \\
\hline Para 5 & 02 & 02 \\
\hline Para $>5$ & 05 & 05 \\
\hline Total & 100 & 100 \\
\hline
\end{tabular}

\section{Bleeding pattern}

Menorrhagia (51\%) was the most common type of presentation in all cases of DUB, followed by metropathia haemorrhagica (MPH) (16\%) and polymenorrhoea (14\%) (Table 3 ).

Table 3: Distribution of cases according to pattern of bleeding $(\mathrm{n}=100)$.

\begin{tabular}{|lll|}
\hline Bleeding pattern & No. of patients & $\%$ \\
\hline Menorrhagia & 51 & 51 \\
\hline $\begin{array}{l}\text { Metropathia } \\
\text { Haemorrhagica }\end{array}$ & 16 & 16 \\
\hline Polymenorrhoea & 14 & 14 \\
\hline Oligomenorrhoea & 10 & 10 \\
\hline Polymenorrhagia & 09 & 09 \\
\hline Total & 100 & 100 \\
\hline
\end{tabular}

Table 4: Distribution of patients according to the thyroid function $(n=100)$.

\begin{tabular}{|lll|}
\hline Thyroid dysfunction & No. of cases & $\%$ \\
\hline Euthyroid & 76 & 76 \\
\hline Hypothyroid & 22 & 22 \\
\hline Hyperthyroid & 02 & 02 \\
\hline
\end{tabular}




\section{Thyroid dysfunction}

Thyroid dysfunction was prevalent in $24 \%$ of DUB patients. The prevalence of hypothyroidism was $22 \%$ and hyperthyroidism was $2 \%$ (Table 4 ).
Percentage of thyroid disorders was more in the age group of 31-40 years (37.5\%), followed by age group above 40 years $(33.33 \%)$. Most of the patients with thyroid dysfunction belonged to para 2-4 (62.5\%) (Table $5)$.

Table 5: Distribution of patients according to thyroid status in relation to age and parity $(\mathrm{n}=100)$.

\begin{tabular}{|llllllllllll|} 
Thyroid & & \multicolumn{2}{c}{ Age in years } & \multicolumn{3}{c}{ Total } & \multicolumn{4}{c}{ Parity } & \multicolumn{3}{c}{ Total } \\
status & $\mathbf{2 0}$ & $\mathbf{2 0 - 3 0}$ & $\mathbf{3 1 - 4 0}$ & $\mathbf{> 4 0}$ & & Unmarried & Nulli & Para 1 & Para 2-4 & Para $\geq \mathbf{5}$ \\
\hline Euthyroid & 01 & 09 & 37 & 29 & 76 & 01 & 02 & 04 & 64 & 05 & 76 \\
\hline Hypothyroid & 01 & 06 & 09 & 06 & 22 & 04 & 02 & 01 & 13 & 02 & 22 \\
\hline Hyperthyroid & 00 & 00 & 00 & 02 & 02 & 00 & 00 & 00 & 02 & 00 & 02 \\
\hline Total & 02 & 15 & 46 & 37 & 100 & 05 & 04 & 05 & 79 & 07 & 100 \\
\hline
\end{tabular}

Table 6: Menstrual disorders in hypothyroid and hyperthyroid patients $(n=24)$.

\begin{tabular}{|llll|}
\hline Bleeding pattern & Hypothyroid $(\mathrm{n}=22)$ & Hyperthyroid $(\mathrm{n}=2)$ & Total $(\mathrm{n}=24)$ \\
\hline Menorrhagia & $12(54.54 \%)$ & $01(50 \%)$ & $13(54.16 \%)$ \\
\hline Metropathia haemorrhagica & $04(18.18 \%)$ & $01(50 \%)$ & $05(20.83 \%)$ \\
Oligomenorrhoea & $03(13.63)$ & - & $03(12.50 \%)$ \\
\hline Polymenorrhoea & $02(09.09 \%)$ & - & $02(08.33 \%)$ \\
\hline Polymenorrhagia & $01(04.54)$ & - & $01(04.16 \%)$ \\
\hline
\end{tabular}

Of the total 22 hypothyroid patients, 12 (54.54\%) had menorrhagia. In 2 patients with hyperthyroidism one each had menorrhagia and MPH. The other menstrual irregularities associated with hypothyroid patients were MPH, oligomenorrhoea, polymenorrhoea and polymenorrhagia (Table 6).

\section{DISCUSSION}

Dysfunctional uterine bleeding is frequently seen to be associated with thyroid abnormalities and in majority of patients, a menstrual abnormality may even precede the occurrence of other clinical signs and symptoms of thyroid dysfunction. Owing to the autoimmune etiology, thyroid disorders in general and hypothyroidism in particular, are more common in women. Patients with severe hypothyroidism had a higher prevalence of menstrual disturbances $(34.8 \%)$, than mild to moderate cases $(10.2 \%)^{4}$

In our study, most of the DUB patients were in the age group of 31-40 years (46\%). This is in concurrence with the study done by Sangeetha et al, and Deshmukh et al, who observed that $42 \%$ and $44 \%$ of patients, respectively, belonged to age group of $31-40$ years. ${ }^{3,5}$ In this study, most of the DUB patients belonged to para $3(36 \%)$, followed by para $2(24 \%)$, similar to the study done by bhavani et al, in which $21.5 \%$ belonged to para 2 and $20.5 \%$ belonged to para 3 . $^{6}$

In present study, thyroid disorders were prevalent in $24 \%$ of DUB patients. Hypothyroidism was seen in $22 \%$, and hyperthyroidism in $2 \%$ of DUB patients, while $76 \%$ were euthyroid. In a study by Padmaleela et al, thyroid disorders were prevalent in $26.5 \%$ of DUB patients. ${ }^{7}$ Hypothyroidism was seen in $18.1 \%$ and hyperthyroidism in $8.4 \%$, while $73 \%$ of DUB patients were euthyroid. In a study conducted by sangeetha et al, of the total 100 cases, $22 \%$ were found to be hypothyroid, $2 \%$ hyperthyroid and the rest euthyroid $(76 \%){ }^{5}$ Hence, the findings in our study are similar to the above two studies.

In present study, the age group in which the thyroid disorders are most commonly seen, belong to 31-40 years (37.5\%). In the study by Sruthi $\mathrm{T}$ et al, most of the thyroid disorders belonged to the age group of 30-40 years $(42 \%) .{ }^{8} \mathrm{~A}$ higher results were seen in the study of Sangeetha $\mathrm{P}$ et al where $54 \%$ of thyroid patients belonged to age group of $31-40$ years. ${ }^{5}$

Most of the patients with thyroid dysfunction belonged to para 2-4 $(62.5 \%)$. This is slightly lower than the result seen in study by Sangeetha Pet al where $83 \%$ of patients with thyroid dysfunction were between para $2-4 .{ }^{5}$

Menorrhagia was the most common menstrual pattern among the DUB patients seen in $51 \%$ of cases, followed by MPH in $16 \%$ and polymenorrhoea in $14 \%$ of cases. In a study by Deshmukh PY et al, the commonest bleeding pattern was menorrhagia $(50 \%) .{ }^{3}$ Similarly, in the study by Bhavani et al, menorrhagia was the commonest pattern of bleeding seen in $54 \%$ of cases. ${ }^{6}$ Hence the bleeding pattern in DUB, in present study, concurs with the findings in the other two studies. 
Of the 22 hypothyroid patients, 12 (54.54\%) had menorrhagia, $4(18.18 \%)$ had MPH, $3(13.63 \%)$ patients had oligomenorrhoea, $2(09.09 \%)$ had polymenorrhoea and $1(04.54 \%)$ had polymenorrhagia. Thus, menorrhagia is the commonest abnormal bleeding pattern in the hypothyroid patients. This is in concurrence with the study of Padmaleela et al where $50 \%$ of hypothyroid patients showed menorrhagia. ${ }^{7}$ Woman with hypothyroidism, commonly present with anovulation and the unopposed oestrogen activity causes endometrial hyperplasia which may outgrow the blood supply and may cause local areas of necrosis that breaks down and produce bleeding. Hence in hypothyroid patient's menstrual abnormality in form of menorrhagia is much more severe and anovulatory cycles are common. ${ }^{9}$

In our study, in 2 patients with hyperthyroidism, one each had menorrhagia and MPH. In the study by Bhavani et al hypomenorrhoea $(33 \%)$, polymenorrhoea (33\%) and menorrhagia $(33 \%)$, were present in hyperthyroid patients. ${ }^{6}$ In various other studies oligomenorrhoea was found to be the most common abnormal bleeding pattern in patients presenting with hyperthyroidism. ${ }^{10,11}$ Thus in hyperthyroid patient's various types of bleeding patterns may exist.

\section{CONCLUSION}

Thyroid disorder should be considered an important etiological factor for menstrual abnormality. Thus, biochemical evaluation for thyroid dysfunction should be made mandatory in DUB cases to detect profound and subclinical thyroid abnormalities. Early diagnosis along with the treatment of thyroid abnormalities will relieve DUB, thus avoiding unnecessary hormonal treatment and hysterectomies.

Funding: No funding sources

Conflict of interest: None declared

Ethical approval: The study was approved by the Institutional Ethics Committee

\section{REFERENCES}

1. Devi J, Aziz N. Study of histopathological pattern of endometrium in abnormal uterine bleeding in the age group 40-60 years. A study of 500 cases. Int J Med Sci Clinic Invent. 2014;1:579-85.

2. Fraser IS, Langham S, Hoschgraebes K. Health related quality of life and economic burden of abnormal uterine bleeding. Expert review Obstet Gynaecol. 2009;4(2):179-89.

3. Deshmukh PY, Boricha BG, Pandey A. The association of thyroid disorders with abnormal uterine bleeding. Int $\mathbf{J}$ Reprod Contracept Obstet Gynecol. 2015;4:701-8.

4. Kakuno Y, Amino N, Kanoh M, Kawai M, Fujiwara M, Kimura $M$ et al. Menstrual disturbances in various thyroid diseases. Endocrinol J. 2010;57:1017-22.

5. Sangeeta P, Shailja G, Jasmine K. Thyroid dysfunction in dysfunctional uterine bleeding. J Adv Res Biol Sci. 2013;5:78-83.

6. Bhavani N, Sathineedi A, Giri A, Chippa S, Prasannakumar Reddy VS. A study of correlation between abnormal uterine bleeding and thyroid dysfunction. Int $\mathbf{J}$ Recent Trends Sci Tech. 2015;14:131-5.

7. Padmaleela K, Thomas V, Lavanya KM, Kiranmai D. Thyroid disorders in Dysfunctional uterine bleeding (DUB) among reproductive age group women- a cross sectional study in a tertiary care hospital in Andhra Pradesh, India. Int J Med Sci. 2013;4:41-6.

8. Sruthi T, Shilpa SB, Gopal N. Prevalence of hypothyroidism in patients with provisional diagnosis of DUB. J Evol Med Dent Sci. 2014;3:2967-72.

9. Somani SR, Somani SG. Study of thyroid dysfunction in premenopausal women with abnormal uterine bleeding. Int J Sci Res. 2015;4:487-9.

10. Bhardwaj M, Bhargava S. Study of thyroid function in dysfunctional uterine bleeding. Natl J Med Dent Res. 2015;4:6-10.

11. Ali J, Das KK, Konyak P. Study of relation of thyroid profile with abnormal uterine bleeding. Sch J App Med Sci. 2015;3:2688-92.

Cite this article as: Usharani N, Shavi K. Clinical study of hypo/hyper thyroidism in dysfunctional uterine bleeding. Int J Reprod Contracept Obstet Gynecol 2017;6:3324-7. 